\title{
Total synthesis and structural elucidation of natural products: (-)-Delactonmycin, (+)-plumerinine, and (-)-parvistemoamide*
}

\author{
Ronaldo A. Pillił, Ivan R. Corrêa Jr., Adriano O. Maldaner, and \\ Giovanni B. Rosso
}

Instituto de Química, Unicamp P.O. Box 6154, 13084-971, Campinas, SP Brazil

\begin{abstract}
Synthetic studies that established the relative configuration of (-)-delactonmycin, a polyketide with inhibitory activity against HIV-1 Rev protein, and our efforts toward the structural elucidation of the alkaloids (+)-plumerinine, isolated from P. rubra, and (-)-parvistemoamide, isolated from $S$. parviflora, are discussed.
\end{abstract}

Keywords: natural products; structural elucidation; delactonmycin; plumerinine; parvistemoamide.

\section{INTRODUCTION}

Over time, organic synthesis has served admirably well for the advancement of our knowledge of life. Since Emil Fischer's legendary work on the chemistry of biomolecules such as carbohydrates, peptides, and purines [1] up to its current level of sophisticated artistic endeavor [2], synthetic organic chemistry has played a definitive role not only in structural determination of natural and non-natural compounds, but has served as the testing ground to invent and test the scope and limitations of synthetic methodologies $[3,4]$. Over the years, our interest in synthetic organic chemistry was initially sustained by the unique biological activities of natural compounds such as pheromones [5], polyketides [6], and alkaloids [7] of established chemical structure and steadily evolved to the structural confirmation of the molecular architecture as we stumbled into some examples of structure misassignment in the literature and became interested in applying our knowledge of stereochemical control to the determination of the configuration of some natural products. What follows is an account of our recent results on the structural elucidation of (-)-delactonmycin [8], (+)-plumerinine [9], and (-)-parvistemoamide.

\section{TOTAL SYNTHESIS AND STRUCTURAL ELUCIDATION OF (-)-DELACTONMYCIN}

In 1997, Wang and coworkers isolated several polyketides from the extracts of Streptomyces strain A92-308902, which displayed nanomolar inhibitory activity against HIV-1 Rev protein during bioassay-guided high-throughput screening [8]. Rev gene is essential for HIV replication, and its protein must be translocated from nucleus to cytoplasm to exert its function and thus could be a potential target for HIV-1 therapy. Among the compounds isolated were some that had been previously reported in the literature, such as leptomycin A (1), leptomycin B (2) [10], kazusamycin A (3), and kazusamycin

*Pure Appl. Chem. 77, 1087-1296. An issue of reviews and research papers based on lectures presented at the $15^{\text {th }}$ International Conference on Organic Synthesis (ICOS-15), held in Nagoya, Japan, 1-6 August 2004, on the theme of organic synthesis.

${ }^{\ddagger}$ Corresponding author: This paper is dedicated to Prof. Albert J. Kascheres and Clayton H. Heathcock for their decisive role in my professional life. 
B (4) [11] and a novel polyketide named delactonmycin, which had its planar structure proposed based on spectroscopic analysis (Fig. 1). Based on its co-occurrence with leptomycins A (1) and B (2), we surmised its absolute configuration as depicted in structure $\mathbf{5}$ and carried out its total synthesis in order to compare the physical data of the natural and synthetic compounds. Additionally, its structural simplicity when compared to the other members of its family renders $\mathbf{5}$ an attractive model compound for structure-activity studies. Finally, a successful approach to the acyclic core of these natural polyketides would pave the way to the total synthesis of other members of this family, which did not have its relative or absolute configuration established [12].

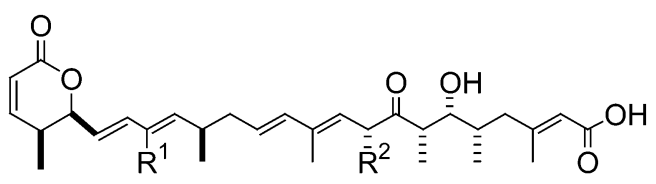

Leptomycin A (1) $\mathrm{R}^{1}=\mathrm{R}^{2}=\mathrm{Me}$

Leptomycin B (2) $\mathrm{R}^{1}=\mathrm{Et}, \mathrm{R}^{2}=\mathrm{Me}$

Kazusamycin A (3) $\mathrm{R}^{1}=\mathrm{Et}, \mathrm{R}^{2}=\mathrm{CH}_{2} \mathrm{OH}$

Kazusamycin B (4) $\mathrm{R}^{1}=\mathrm{Me}, \mathrm{R}^{2}=\mathrm{CH}_{2} \mathrm{OH}$<smiles>CC=C(C)C[C@@H](C)[C@H](O)[C@@H](C)C(=O)[C@@H](C)C=C(C)C=CCC(C)C(=O)O</smiles>

Delactonmycin (5)

Fig. 1

Our approach to 5 was based on methyl 3-hydroxy-2-methylpropanoate as the chiral starting material and on the $\mathrm{Sn}(\mathrm{OTf})_{2}$ mediated aldol reaction of chiral ethyl ketone 6, prepared from methyl $(R)$-3-hydroxy-2-methylpropanoate along the lines described by Paterson and Arnott [13], and chiral aldehyde 9. Several routes were explored in order to achieve a preparatively useful access to $\gamma, \delta$-aldehyde 9, and the best one in our hands was based on the methodology developed by Kuwajima and coworkers [14] and involved the $\operatorname{Pd}(0)$-catalyzed cross-coupling reaction between chiral zinc homoenolate 7 and $(E)$-2-bromo-2-butene to provide unsaturated methyl ester $\mathbf{8}$ in $93 \%$ yield, which was uneventfully converted to aldehyde 9 upon DIBAL reduction (Scheme 1). The key transformation to hydroxyketone $\mathbf{1 0}$ (75\% yield, 96:4 d.r.) was achieved upon treating ethyl ketone $\mathbf{6}$ with $\mathrm{Sn}(\mathrm{OTf})_{2}$ and $\mathrm{Et}_{3} \mathrm{~N}$ in $\mathrm{CH}_{2} \mathrm{Cl}_{2}$ at $-78{ }^{\circ} \mathrm{C}$, followed by the addition of aldehyde 9 (Scheme 1).<smiles>COC(=O)[C@H]1C[C@@H](Br)[C@H]1Br</smiles>

7

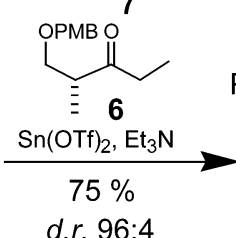

d.r. $96: 4$

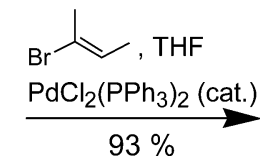

$93 \%$<smiles>C/C=C(/C)C[C@H](C)[C@H](O)[C@@H](C)C(=O)[C@H](C)CO[Na]</smiles>

10<smiles>C/C=C(/C)C[C@H](C)C(=O)OC</smiles>

8

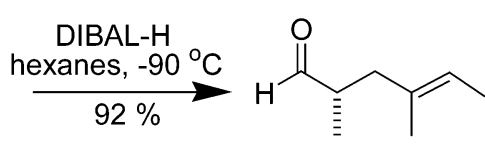

9

\section{Scheme 1}

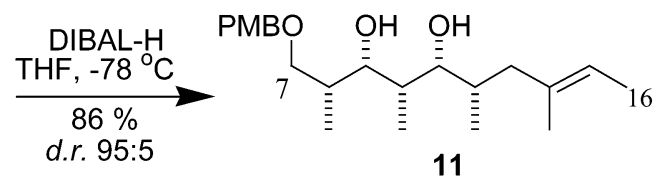

With an efficient entry to the C7-C16 fragment of delactonmycin (5) secured, we embarked on the installation of the diene moiety, which was planned to involve two sequential $E$-selective Wittig olefinations. As prudence would dictate, we decided to hide the carbonyl function at C9 (delactonmycin numbering) as the corresponding alcohol 11, which would be uncovered later on in the synthetic 
scheme. After convincing evidence of the 3,5-syn diol pattern in 11 was gathered from NMR studies on the corresponding 9,11-isopropylidene acetal, we took advantage of the $p$-methoxybenzyl (PMB) ether embedded in $\mathbf{1 1}$ and carried out its oxidative conversion to the corresponding $p$-methoxybenzylidene acetal 12, allowing the secondary alcohol at $\mathrm{C} 11$ to be masked as the corresponding TBS ether. Reductive opening of the $p$-methoxybenzylidene acetal ornament in $\mathbf{1 2}$ revealed primary alcohol $\mathbf{1 3}$ (52\% overall yield, 4 steps). At this point, we were quite satisfied with the overall conversion of hydroxyketone $\mathbf{1 0}$ to a protected form of its corresponding triol, which seemed to fit just nice with our synthetic plans. As often happens, we were not quite aware of the high toll to be collected afterwards as a consequence of our choice of a PMB ether as the protecting group for the secondary hydroxyl group at C9! Quite confident of our chances, we proceeded swiftly to install the insaturation adorning structure $\mathbf{5}$ after oxidation of alcohol $\mathbf{1 3}$ to the corresponding aldehyde and olefination with a stabilized Wittig reagent in toluene. The requisite $(E, E)$-diene moiety was installed after conversion of unsaturated ester 14 to the corresponding tri- $n$-butylphosphonium salt via its allylic bromide and reaction of the corresponding ylide with aldehyde 15 (prepared from methyl (S)-3-hydroxy-2-methylpropanoate). The requisite $(E, E)$-diene $\mathbf{1 6}$ was isolated in $58 \%$ overall yield from $\mathbf{1 4}$ as a 8:1 mixture of the two possible geometric isomers (Scheme 2).
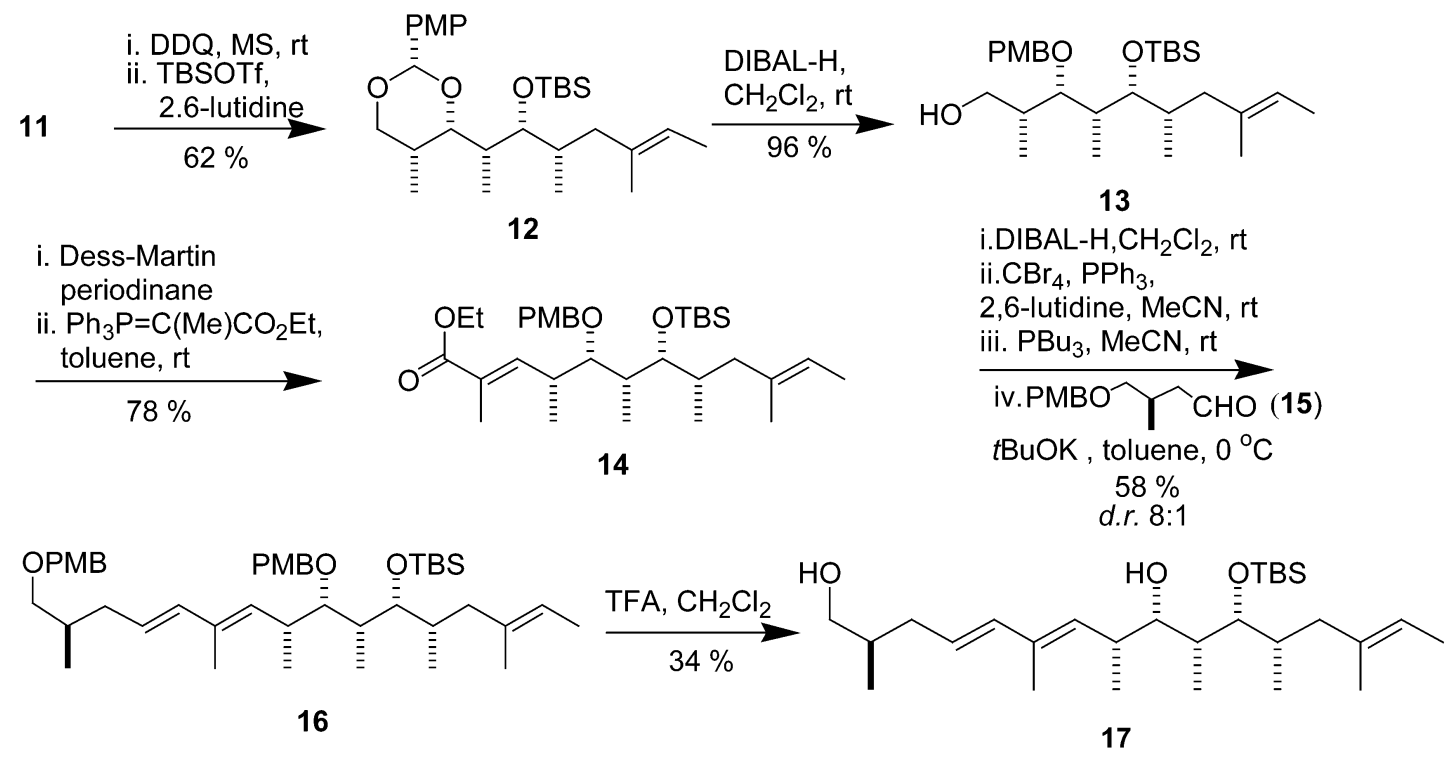

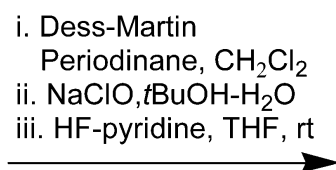

Scheme 2

The resource of employing two PMB groups had been planned to allow for their simultaneous removal at this stage of the synthesis. We had not anticipated the burden associated with removal of such a ubiquitous protecting group in the realm of a triene scaffold (actually, a 1,3-diene moiety!). This unanticipated hurdle forced us to evaluate different protocols available in the literature to eventually find out that trifluoroacetic acid in $\mathrm{CH}_{2} \mathrm{Cl}_{2}$ provided diol 17 in low but reproducible $34 \%$ yield. Touched by some mixed feelings as we approached the proposed structure for natural delactonmycin, we put into 
motion the final attack, which involved oxidation of diol $\mathbf{1 7}$ to the corresponding carboxylic acid and exposition of the secondary hydroxyl group at C11, which indeed afforded carboxylic acid $\mathbf{5}$ in $48 \%$ yield from diol 17 (Scheme 2). Our bad feelings and apprehension disappeared as we compared the NMR data of the synthetic sample and of natural delactonmycin kindly provided by Dr. Wang, as it left no doubt about the identity of the two samples. The relative configuration of the natural product had thus been established, although the lack of chiroptical data for the natural compound precluded us from confirming its absolute configuration at this point [8].

\section{STRUCTURAL ELUCIDATION OF (+)-PLUMERININE: THE UNSOLVED PUZZLE}

Plumeria rubra (Apocynaceae), a common ornamental plant in Southeast Asia and in Brazil, is claimed to have a variety of biological activity ranging from purgative, diuretic, abortifacient to antituberculosis activities. In 1989, Malik and coworkers reported on the isolation of a quinolizidine alkaloid from the freshly collected stems of $P$. rubra, and based on spectroscopic studies structure $\mathbf{1 8}$ has been assigned to this alkaloid, which was named plumerinine [9]. Recently, Comins and coworkers [15] devised a stereocontrolled total synthesis of (+/-)-18 and showed that its NMR data differs from natural plumerinine, casting doubt on the structure put forth by Malik and coworkers for the natural product. Attracted by the puzzle involving the structure of plumerinine and by the possibility of making good use of $\mathrm{N}$-acyliminium methodology previously developed in our laboratory [7], we decided to embark on a program aiming to prepare quinolizidinones (+/-)-19a and/or (+/-)-19b (Fig. 2).

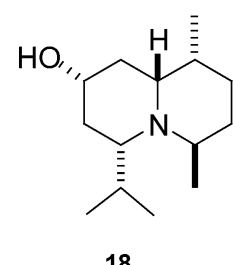

18

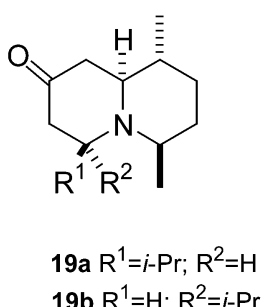

$19 \mathrm{~b} \mathrm{R}^{1}=\mathrm{H} ; \mathrm{R}^{2}=i-\mathrm{Pr}$

Fig. 2

Our original synthetic plan entailed the stereoselective addition of a silyloxydiene (to be prepared from commercially available (E)-5-methyl-hex-3-en-2-one) to 2,5-trans-disubstituted $\mathrm{N}$-acyliminium ion derived from 21 [16], which was expected to afford the alkylated $N$-Boc-piperidine 22 as the major product (Scheme 3). In fact, our expectations were borne out and $\mathbf{2 2}$ was isolated in $86 \%$ yield displaying axial disposition of its substituents in order to relieve the $\mathrm{A}(1,3)$ strain involving the substituents at $\mathrm{C} 2$ and $\mathrm{C} 6$ and the tert-butylcarbamate (nuclear Overhauser effect-NOE-studies). Upon $\mathrm{N}$-Boc deprotection (TFA in $\mathrm{CH}_{2} \mathrm{Cl}_{2}$ ), the equatorial disposition of the substituents prevailed, but to our dismay we could not coax the system to undergo intramolecular Michael addition at room temperature. After evaluating several different experimental conditions, we learned that the desired 6-endo-cyclization required heating with aq. $\mathrm{NH}_{3}$ in $\mathrm{MeOH}$ at $60{ }^{\circ} \mathrm{C}$ for $24 \mathrm{~h}$, yielding the cyclization product in $35-40 \%$ yield. Its recalcitrant nature was not the only surprise concealed by the quinolizidinone derived from $N$-Boc-carbamate 22: despite the cis-2,6-dialkyl relationship in $N$-Boc-piperidine 22, we soon realized that the product of intramolecular Michael reaction did not conserve the relative stereochemistry at C9a (quinolizidinone numbering). In fact, quinolizidinone 19a, which is expected by theoretical calculations to adopt the cis-ring fusion, cannot accommodate the NOE results collected during our spectroscopic analyses: irradiation at $\mathrm{H} 9 \mathrm{a}(\delta 3.12)$ led to an increment in the signal of the methyl $(1.1 \%)$ and methyne $(2.2 \%)$ hydrogens of the isopropyl group at $\mathrm{C} 4$, while irradiation at $\mathrm{H} 4(\delta 2.96)$ significantly increased the signal of the methyl group at C6 (2.9\%). Although the structure of quinolizidinone 19b, predicted to exist mainly in the cis-fused conformation, can explain to some extent the 


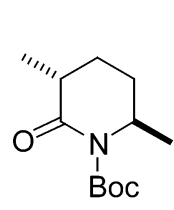

20

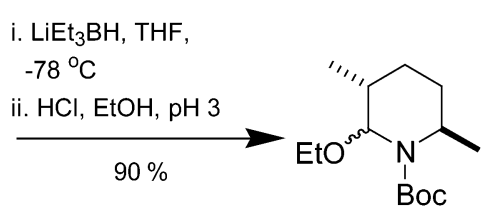

21

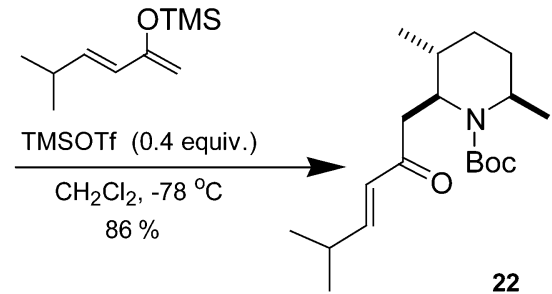

22

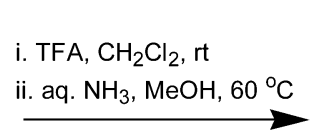<smiles>CC(C)C1CC(=O)C[C@@H]2[C@@H](C)CC[C@H](C)N12</smiles>

23

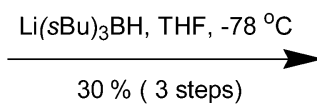<smiles>[R7]C1([R2])C[C@@H](C(C)C)N2[C@@H]([C@@H](C)CC[C@H]2C)[C@H]1C</smiles>

$24 \mathrm{R}^{1}=\mathrm{OH}, \mathrm{R}^{2}=\mathrm{H}$ $25 \mathrm{R}^{1}=\mathrm{H}, \mathrm{R}^{2}=\mathrm{OH}$

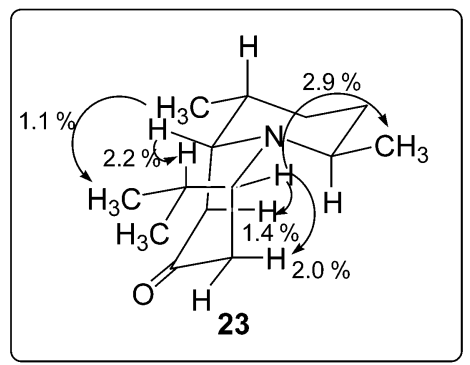

Scheme 3

above NOE data, irradiation at $\mathrm{H} 6$ produced a $2.0 \%$ increment in the $\mathrm{H}-3 \alpha$ signal $(\delta 2.51)$ and $1.4 \%$ increment in the $\mathrm{H} 1 \alpha$ double doublet $(\delta 2.45)$, which is not consistent with structure $19 \mathrm{~b}$ but is nicely accommodated by quinolizidinone $\mathbf{2 3}$, which was shown by molecular mechanics and semi-empirical methods to exist preferentially in the cis-fused conformation where $\mathrm{H} 6, \mathrm{H} 1 \alpha$, and $\mathrm{H} 3 \alpha$ are in close proximity. This unexpected outcome was rationalized by epimerization of the stereocenters at $\mathrm{C} 4$ and C9a in the kinetically controlled quinolizidinone initially formed (either 19a or 19b) via retroMichael/Michael and retro-Mannich/Mannich manifolds leading to the thermodynamically more stable quinolizidinone 23. Reduction of the carbonyl group with $\mathrm{Li}(s-\mathrm{Bu})_{3} \mathrm{BH}$ provided a single product that was established as the axially oriented alcohol $\mathbf{2 4}$ (30\% overall yield from 22 ) while the use of $\mathrm{LiAlH}_{4}$ afforded a 1.2:1 mixture (49\% yield) of alcohols $\mathbf{2 4}$ and $\mathbf{2 5}$. Comparison of their NMR data with those reported for (+)-plumerinine revealed the non-identity between the natural product and synthetic $\mathbf{2 4}$ and $\mathbf{2 5}$, leaving the puzzle of the structural assignment of (+)-plumerinine unsolved [9].

\section{TOTAL SYNTHESIS OF (+/-)-PARVISTEMOAMIDE: A BIOMIMETIC ROUTE TO STEMOAMIDE?}

Stemonaceae (order Dioscoreales) is a small monocotyledoneous family comprising three small genera: Stemona, Croomia, and Stichoneuron. Herbal extracts from various plants belonging to the Stemonaceae family have been used for the treatment of respiratory diseases and as anthelmintic in China and other East Asia countries for thousands of years. The Stemona alkaloids represent a class of polycyclic alkaloids with relatively complex structure, and most of them are structurally characterized by the presence of a pyrrolo[1,2- $a$ ]azepine or, as revealed recently, a pyrido[1,2-a]azepine nucleus $[17,18]$. A limited number of Stemona alkaloids either lacks or have a hidden pyrrolo[1,2-a]azepine architecture, which can only be revealed upon cleavage or formation of $\mathrm{C}-\mathrm{C}$ or $\mathrm{C}-\mathrm{N}$ bonds. 
Parvistemoamide is one of these alkaloids lacking the pyrrolo[ $[1,2-a]$ azepine architecture, which has been isolated from $S$. parviflora by $\mathrm{Xu}$ and coworkers and had its relative configuration established by 2D-NMR studies. However, structures $\mathbf{2 6}$ and $\mathbf{2 7}$ displaying different configurations at C9a and C10 were reported for parvistemoamide, which makes it structural assignment ambiguous (Fig. 3) [19]. Our interest in the total synthesis of structures (+/-)-26 and (+/-)-27 was fueled not only by this discrepancy, but also by a possible biomimetic conversion of $\mathbf{2 7}$ to stemoamide (28) via oxidation at C9a, nucleophilic attack by an activated form of the amide nitrogen, followed by dehydration and reduction of the intermediate $N$-acyliminium ion (Fig. 4).<smiles>CC1C(=O)OC2CCCNC(=O)CCC21</smiles>

26<smiles></smiles>

27

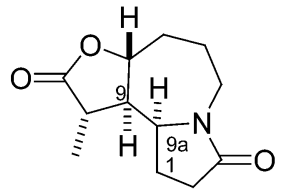

(+/-)-Stemoamide (28)

Fig. 3

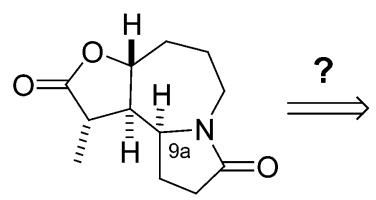

28<smiles></smiles>

27

Fig. 4

Our synthetic plan was based on the trans-selective Michael addition between furanone (+/-)-31 and nitroester 32, which could be carried out with a catalytic amount of DBU in MeCN at room temperature to afford the trans-Michael adduct in $65 \%$ yield (Scheme 4). Nef oxidation with potassium permanganate adsorbed on silica gel in refluxing benzene provided (+/-)-33 in $45 \%$ yield (30\% overall yield from (+/-)-31). Despite the moderate overall yield of the whole sequence, it provided an expeditious access to (+/-)-33, which bears all the carbons necessary for the construction of (+/-)-26 and $(+/-)-27$. Catalytic hydrogenation in acetic acid and $\mathrm{PtO}_{2}$ as catalyst triggered a cascade of events including reduction of the cyano and keto groups (although not necessarily in this order) and lactamization to provide a 5:1 mixture of two lactams that had their structures proposed based on spectroscopic studies: comparison of the ${ }^{1} \mathrm{H}$ NMR data of natural parvistemoamide with those of the minor isomer $(+/-)-27$ revealed them as spectroscopically distinct chemical entities, while the major isomer was assigned as 10-epi-26 based on NOE studies collected during our spectroscopic analyses: irradiation at H8 $(\delta$ 4.20) led to a significantly increment $(4.4 \%)$ at H10 (which is not consistent with structure 26 proposed for the natural product) but no increment at $\mathrm{H} 9 \mathrm{a}$ and the methyl group at $\mathrm{C} 10$. Further studies are underway in order to definitively establish the relative and absolute configurations of (-)-parvistemoamide. 

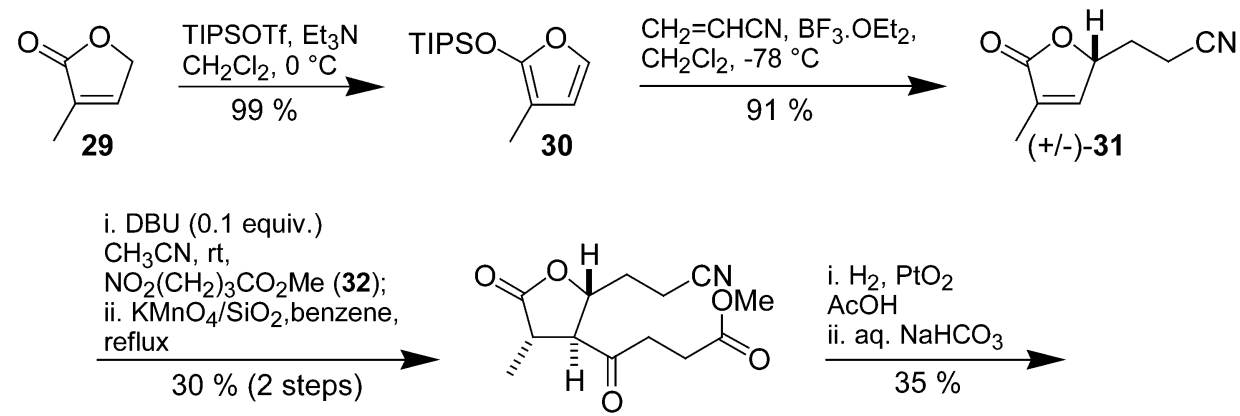

(+/-)-33<smiles>C[C@@H]1C(=O)O[C@H]2CCCNC(=O)CC[C@@H](O)[C@H]1[C@H]2O</smiles>

(+/-)-10-ері-26

(+/-)-27

Scheme 4

\section{FINAL REMARKS}

The enormous progress in analytical methods over the last decades has definitively changed the art of structural elucidation of natural and non-natural compounds to a point where organic synthesis is not at the center of the stage anymore. Despite its wide scope, physical methods are not devoid of limitations and errors, and examples of wrong structural assignment based solely on spectroscopic methods (including some where X-ray analysis has been employed) have been reported in the literature. The synthetic organic chemist has the choice to use his/her skills to judiciously analyze the available physical data for a natural or non-natural chemical entity and decide to launch a research program aimed at structural elucidation by total synthesis. Compared to the approach based only on physical methods, one may certainly get several extra bonuses by deciding to take the synthetic road, as such an endeavor not only allows one to gather data on the chemical properties of the target product and its precursors, but more often than not, it allows a better understanding of the reaction mechanisms and of the scope and limitations of the available methodologies and exposes the need for the invention and discovery of new methodologies. The relative configuration of delactonmycin was established as $\mathbf{5}$ by a successful combination of asymmetric aldol reaction and Wittig olefination methodologies. Our attempts to elucidate the stereochemistry of the alkaloids plumerinine and parvistemoamide has not met with success yet, but we have been able to devise short accesses to the main skeleton for both of them, which should enable us to continue investigating their intriguing chemical nature.

\section{ACKNOWLEDGMENTS}

This work was made possible by the efforts of a talented and dedicated group of collaborators whose names appear in the list of references. These and many others have contributed with ideas and attitudes to the continuing growth of our interest in organic synthesis. Financial support has been provided by Fapesp and CNPq. 


\section{REFERENCES}

1. F. W. Lichtenthaler. Eur. J. Org. Chem. 4095 (2002).

2. (a) K. C. Nicolaou and E. J. Sorensen. In Classic in Total Synthesis, Wiley-VCH, Weinheim (1996); (b) K. C. Nicolaou and S. A. Snyder. In Classics in Total Synthesis II. Targets, Strategies, Methods, Wiley-VCH, Weinheim (2003).

3. K. C. Nicolaou and P. S. Baran. Angew. Chem., Int. Ed. 41, 2679 (2002).

4. P. A. Wender, J. L. Baryza, S. E. Brenner, M. O. Clarke, G. G. Gamber, J. C. Horan, T. C. Jessop, C. Kan, K. Pattabiraman, T. J. Williams. Pure Appl. Chem. 75, 143 (2003).

5. (a) R. A. Pilli and M. M. Murta. J. Org. Chem. 58, 338 (1993); (b) R. A. Pilli, C. K. Z. de Andrade, C. R. de O. Souto, A. de Meijere. J. Org. Chem. 63, 7811 (1998); (c) R. A. Pilli and M. M. Victor. Tetrahedron Lett. 39, 4421 (1998).

6. R. A. Pilli, M. M. Victor, A. de Meijere. J. Org. Chem. 65, 5910 (2000).

7. (a) R. A. Pilli, L. C. Dias, A. O. Maldaner. J. Org. Chem. 60, 717 (1995); (b) R. A. Pilli and D. Russowsky. J. Org. Chem. 61, 3187 (1996); (c) R. A. Pilli and G. B. Rosso. In Science of Synthesis. Houben-Weyl Methods of Molecular Transformations, Vol. 27, A. Padwa (Ed.), p. 375, Georg Thieme Verlag (2004).

8. I. R. Corrêa, Jr. and R. A. Pilli. Angew. Chem., Int. Ed. 42, 3017 (2003).

9. A. O. Maldaner and R. A. Pilli. Synlett 1343 (2004).

10. (a) T. Hamamoto, S. Gunji, H. Tsuji, T. Beppu. J. Antibiot. 36, 639 (1983); (b) T. Hamamoto, H. Seto, T. Beppu. J. Antibiot. 36, 646 (1983).

11. (a) K. Funaishi, K. Kawamura, Y. Sugiura, N. Nakahori, E. Yoshida, M. Okanishi, I. Umezawa, S. Funayama, K. Komiyama. J. Antibiot. 40, 778 (1987); (b) K. Takamiya, E. Yoshida, T. Takahashi, A. Okura, M. Okanishi, K. Komiyama, I. Umezawa. J. Antibiot. 41, 1854 (1988); (c) I. Umezawa, K. Komiyama, H. Oka, K. Okada, S. Tomisaka, T. Miyano, S. Takano. J. Antibiot. 37, 706 (1984); (d) K. Komiyama, K. Okada, H. Oka, S. Tomisaka, T. Miyano, S. Funayama, I. Umezawa. J. Antibiot. 38, 220 (1985); (e) K. Komiyama, K. Okada, Y. Hirokawa, K. Masuda, S. Tomisaka, I. Umezawa. J. Antibiot. 38, 224 (1985).

12. M. Kalesse and M. Christmann. Synthesis 981 (2002).

13. I. Paterson and E. A. Arnott. Tetrahedron Lett. 39, 7185 (1998).

14. Y. Tamaru, H. Ochiai, T. Nakamura, K. Tsubaki, Z.-I. Yoshida. Tetrahedron Lett. 26, 5559 (1985).

15. D. L. Comins, X. L. Zheng, R. R. Goehring. Org. Lett. 4, 1611 (2002).

16. R. A. Pilli and A. O. Maldaner. Tetrahedron 55, 13321 (1999).

17. (a) R. A. Pilli and M. C. F. de Oliveira. Nat. Prod. Rep. 17, 117 (2000); (b) R. A. Pilli, M. C. F. de Oliveira, G. B. Rosso. In The Alkaloids, Vol. 62, G. A. Cordell (Ed.), p. 77, Academic Press, New York (2005).

18. (a) P. Mungkornasawakul, S. G. Pyne, A. Jatisatienr, D. Supyen, W. Lie, A. T. Ung, B. W. Skelton, A. H. White. J. Nat. Prod. 66, 980 (2003); (b) E. Kaltenegger, B. Brem, K. Mereiter, H. Kalchhauser, H. Kählig, O. Hofer, S. Vajrodaya, H. Greger. Phytochemistry 63, 803 (2003).

19. (a) W.-H. Lin, R.-S. Xu, Q.-X. Zhong. Acta Chim. Sin. 49, 927 (1991); (b) R.-S. Xu, Z.-J. Tang, S.-C. Feng, Y.-P. Yang, W.-H. Lin, Q.-X. Zhong, Y. Zhong. Mem. Inst. Oswaldo Cruz 86, Suppl. II, 55 (1991). 